\title{
A New Reality: Human Evolution for a Sustainable Future. By Jonas Salk, MD, and Jonathan Salk, MD. City Point Press: Stratford, CT, USA, 2018; 256pp.; ISBN: 978-1-947951-04-4
}

\author{
Susan L. Prescott ${ }^{1,2, *}$ and Alan C. Logan 2 (1) \\ 1 School of Medicine, University of Western Australia, Perth WA 6001, Australia \\ 2 inVIVO Planetary Health, Worldwide Universities Network (WUN), West New York, NJ 07093-9992, USA; \\ aclnd@cfs-fm.org \\ * Correspondence: Susan.Prescott@telethonkids.org.au
}

Received: 1 July 2018; Accepted: 9 July 2018; Published: 12 July 2018

The name, Jonas Salk, is synonymous with the transition to a new era of personal, public, and planetary health. Best known for the near-eradication of polio, he helped usher in a new age of immunization for infectious disease prevention through individual and 'herd' immunity. In doing this, he also became known and admired for his desire to share the 'wealth' of medical breakthroughs throughout society. Famously, on the announcement of the polio vaccine success (12 April 1955), when asked who holds the patent, he responded by saying "Well, the people, I would say. There is no patent. Could you patent the sun?" [1]. Less known, however, is the remarkable way in which he devoted the next forty years of his life to far broader concepts of human development, by building resilience through a deeper understanding of interdependence and mutualism.

In an age of new, vast, and mounting challenges to human health as a result of social upheaval, lifestyle pressures, and environmental degradation, Salk underscored the need for societal transformation - in essence, 'immunization' of another kind, for a new age of resilience through a new point of social equilibrium. He maintained that the world was entering a new Epoch, a time of change in which the herd (and the ecosystems in which we live) needs to be protected via other 'vaccination' programs, including an early-life understanding of ecological balance, cooperation, and protection of planetary health - a term he used long before it was in the lexicon of science and medicine [2]. He advocated for a distinct United States 'Research Fund for Human Welfare' in which government spending directed at militarization, space races, and defense should be matched-dollar for dollar-to support research in health promotion, education, and improvement in human wellbeing. The point of this was two-fold: First, to understand and identify ways to reduce hate, aggression, segregation, conflict, and incivility (and increase altruism and empathy). Second, the very act itself would send a societal message that mutualism matters; it would be an act that "would remind the nation of its commitment to humanity" [3].

In 1981, Jonas Salk and his son, the psychiatrist Jonathan Salk, penned a forward-thinking book entitled World Population and Human Values: A New Reality (Harper and Row 192 pp; ISBN-13: 978-0060137786); the book explored biological studies involving population expansion and the contraction of different organisms based on environmental resources. Based on this, it was proposed that humans were emerging from their first historical Epoch and into a new Epoch (which they referred to as Epoch A and Epoch B, respectively). While Epoch A was characterized by living life with a perception of unlimited resources and energy, and benefits from population growth, Epoch B is a new era in which there is a distinct awareness of limitations and the need to adapt to a future where the population growth will slow and even plateau. 
Now, almost 40 years on, Jonathan Salk (with the help of architect David Dewane) has updated and expanded the book; now titled, A New Reality: Human Evolution for a Sustainable Future (City Point Press: Stratford, CT, USA, 2018; 256pp.; ISBN: 978-1-947951-04-4). The original concepts are reinforced with new insights, elegantly presented graphs, stunning color photographs, which capture the human condition, and, perhaps most importantly, critical commentary. The authors again provide examples of studies involving microbiota and the animal kingdom to demonstrate the (initial) slow growth of populations, then rapid acceleration, followed by a plateau. Although the human experience is far more complex-highly dependent upon technological, socioeconomic, political, and cultural interplay-there are now clear signs that the global pattern (as exemplified by changes in so-called developed nations) is following a similar trajectory through the end of the 21st century. In the context of human history, evolution, and the cult of progress built upon the term 'growth', the implications of these changes are many.

The title of the book derives from historical perceptions of reality vs. the changing external realities that are now staring us in the face, not only through hard data and 'environmental impact assessments', etc., but through the very visible ways in which the total environment is changing. Changing weather patterns, rapid urbanization, and loss of insect life (and biodiversity in general) are part of a new reality that demands a sense (manifest into behavior) of urgency. Almost 40 years of accumulated research, as well as simply looking around at the reality of the Anthropocene, have not only validated the original effort of this book (1981), but have magnified its importance. As stated by Drs Salk: "our actions now and in the coming decades will determine whether we make the necessary change in human-to-human relationships ... our strongest weapon against these [threats to planetary health] is the promotion of human health, hope, and fulfillment of all human beings".

Obviously, father and son Salk are not the first to make such a plea; they have, however, done so in a form that uniquely contextualizes the imploration; the new book systematically builds the case for a new era in which "new relationships, new communities, and new modes of interacting will emerge and be integrated with developments in science, technology, economics, the arts, and international relations". Included in this is a greater understanding of our relationships to nature (other species and the natural environment-at-large), one another, and the self. The book dismantles the flimsy walls that create untenable separations (and conflicts) between the natural sciences, humanities, and the arts; the new Epoch will require mutualism and a "reconciliation of these divisions and the development of integrative, interdisciplinary approaches to human problems, human thought, and human creativity". The artistic presentation of the graphs-which break down complexity into clearly digestible knowledge-and the photographic plates that accompany the text immediately 'illustrate' the role of the arts in science communication.

The book includes concise, two-page summaries after each of the main sections; an Epilogue entitled "A Favorable Outcome" provides hope for adaption to the new reality. Although it is listed at 256 pages, the book is heavy on imagery and light on text, making it an easy read; while some critics may be unsatisfied that the book lacks specific prescriptions for change, the book is much more like a compass that points in the direction of the pathway to find solutions. Specifically, the authors are emphasizing that whatever specific plans unfold—and they certainly need to-solutions must emerge from an integrative collective, which understands that the "demands for survival [now] converge with the higher ideals of humankind and the well-being and flourishing of human society".

The simplicity, colorful design, limited text per-page, and lack of unnecessary jargon will have appeal to young readers. Indeed, if it were required reading in pre-university level teaching, it would allow students in the arts to understand the importance of (and an appreciation for) the natural sciences and vice versa. Not simply an abstract appreciation, but a working appreciation of creative input. From the perspective of early-life education, A New Reality is the antidote to the obsession with the narrowly defined "STEM" (science, technology, engineering, and math); rather, it explains why we need to focus on the end-game of such investments. Whose science? What technology? For a young student, those questions will be easier to answer after reading A New Reality. 
True to its name, this is a book of transformation, designed not only to inform, but to inspire change. In an increasingly turbulent world, it offers a much needed perspective, and a firm, but well-balanced, call to action. It calls on the visionary writings of one of the most significant heroes of modern medicine, compiled in an elegant, engaging, and accessible format. With necessary urgency, A New Reality provides a vital contribution to the building momentum towards a new era of social consciousness. The book represents a gateway to understanding planetary health. As a unifying resource, it will have widespread appeal and increase the odds that more and more individuals and groups understand that there is no distinction between the health of person, place, and planet. The legacy of Jonas Salk in relation to immunization will extend to a much further reach thanks to this big, little book.

\section{References}

1. Salk, J.; New York, NY, USA. CBS National Interview with Edward R. Murrow. Personal interview, 12 April 1955.

2. Prescott, S.L.; Logan, A.C. Down to Earth: Planetary Health and Biophilosophy in the Symbiocene Epoch. Challenges 2017, 8, 19. [CrossRef]

3. Salk, J. Research fund for human welfare. Daily Press 1966, 71, 34.

(C) 2018 by the authors. Licensee MDPI, Basel, Switzerland. This article is an open access article distributed under the terms and conditions of the Creative Commons Attribution (CC BY) license (http:/ / creativecommons.org/licenses/by/4.0/). 